using data from the ENRICHD trial. In the MIND-IT study we recently confirmed that non-response to mirtazapine and citalopram was associated with more cardiovascular events compared with responders and even untreated controls, a finding that remained after controlling for several confounders, including early cardiovascular events (de Jonge et al, 2007). However, as it is unclear what factors are related to response to antidepressive medication (these may well include the presence of somatic symptoms of depression; Tylee \& Gandhi, 2005), it also remains uncertain whether it might be an improved state of the heart disease that influences depression or reversely that treatment of depression results in an improved cardiovascular prognosis. However, although causality remains unproven it suggests that more effective treatments may have cardiovascular effects as well. We are not yet convinced that this will be ECT but we encourage researchers to explore this possibility.

Carney, R. M., Blumenthal, J. A., Freedland, K. E., et al (2004) Depression and late mortality after myocardial infarction in the Enhancing Recovery in Coronary Heart Disease (ENRICHD) Study. Psychosomatic Medicine, 66, 466-474

De Jonge, P., van den Brink, R. H. S., Spijkerman, T. A., et al (2006a) Only incident depressive episodes following myocardial infarction are associated with new cardiovascular events. Journal of the American College of Cardiology, 48, 2204-2208.

De Jonge, P., Ormel, J., van den Brink, R. H. S., et al (2006b) Symptom dimensions of depression following myocardial infarction and their relationship with somatic health status and cardiovascular prognosis. American Journal of Psychiatry, 163, 138-144.

De Jonge, P., Honig, A., van Melle, J. P., et al (2007)

Non-response to treatment for depression following myocardial infarction is associated with subsequent cardiac events. American Journal of Psychiatry, 164 |37|-1378.

Grace, S. L., Abbey, S. E., Kapral, M. K., et al (2005) Effect of depression on five-year mortality after an acute coronary syndrome. American Journal of Cardiology, 96, 1179-1185.

Tylee, A. \& Gandhi, P. (2005) The importance of somatic symptoms in depression in primary care. Journal of Clinical Psychiatry, 7, 167-176.

P. de Jonge Department of Internal Medicine and Department of Psychiatry, University Medical Center Groningen, The Netherlands. Email: p.d.jonge@med.umcg.nl

J. P. van Melle Department of Cardiology,

Thoraxcenter, University Medical Center Groningen, The Netherlands

J. Ormel Department of Social Psychiatry and Psychiatric Epidemiology, University Medical Center Groningen, The Netherlands

doi: 10.1192/bjp.191.5.456a

\section{Substance misuse disguised as ADHD?}

Attention-deficit hyperactivity disorder (ADHD) is a rather novel disease in adults. It has drawn increasing attention and at present there is no deficit of studies of ADHD in adults (Fayyad et al, 2007). Several studies have shown a considerable risk of co-occurring substance misuse in adults given the diagnosis of ADHD (Aanonsen, 1999; Wilson, 2007). Symptoms of ADHD seem to hamper success in methadone maintenance treatment (Kolpe \& Carlson, 2007). Fayyad et al indicate in Table 5 that in $99 \%$ of cases adult ADHD occurs first in patients with a co-occurring substance use disorder but this is not commented upon in the discussion part of their paper. Respondents were classified retrospectively as having met full ADHD criteria in childhood. To ascertain the presence of ADHD in adulthood respondents were asked a single question only, whether they continued to have problems with attention or hyperactivity.

In Norway we have an impression that people with substance misuse tend to ask for a diagnosis of ADHD, as this may lead to better treatment within the psychiatric care system. The finding of Fayyad et al of higher prevalences in high-income countries, with purportedly better services for the treatment of ADHD, may be an indication of common presenting symptoms in substance use disorder and ADHD. Could the authors have observed symptoms and behaviour related to substance misuse and not ADHD?

\section{Aanonsen, N. O. (1999) Sentralstimulerende legemidler og misbrukspotensial ved hyperkinetisk forstyrrelse. Tidsskrift for den Norske Lægeforening, II9, 4040-4042.}

Fayyad, J., De Graaf, R., Kessler, R. C., et al (2007) Cross-national prevalence and correlates of adult attention-deficit hyperactivity disorder. British Journal Psychiatry, 190, 402-409.

Kolpe, M. \& Carison, G. (2007) Influence of attentiondeficit/hyperactivity disorder symptoms on methadone treatment outcome. American Journal of Addiction, $\mathbf{1 6}$ $46-48$.

Wilson, J. (2007) ADHD and substance use disorders: developmental aspects and the impact of stimulant treatment. American Journal on Addictions, 16 (suppl. I), $5-11$.

J. E. Berg Department of Psychiatry, Lovisenberg Diakonale Hospital, Oslo, Norway. Email: john@pong.no doi: 10.I192/bjp.19I.5.457
Authors' reply Dr Berg raises the possibility that respondents in our surveys who reported persistence of ADHD in adulthood might actually have had symptoms caused by some other disorders, such as alcoholism, that are more stigmatising and less likely to be treated than ADHD. Such respondents might consciously have provided incorrect information in an effort to avoid stigma and to increase their chances of receiving treatment. Dr Berg states that such machinations occur in his country. This is an important point in view of the stigma associated with mental disorders and the fact that some healthcare systems discriminate against certain diagnoses. Mental health professionals need to increase their efforts to raise awareness and address these problems.

That said, it strikes us as implausible that our findings are importantly affected by the sort of bias proposed by Dr Berg. First, the World Mental Health surveys are community epidemiological surveys in which no treatment is provided. Second, in a number of the participating countries ADHD is not commonly recognised as an illness, making it unlikely that community respondents would have the sophistication to seek out this diagnosis. Third, we carried out in-depth clinical reappraisal interviews with a probability sub-sample of respondents who reported adult persistence of ADHD. We excluded respondents if concerns existed that another diagnosis might be primary. Although it is possible that some respondents were so familiar with ADHD that they tricked our experienced clinical interviewers, we consider it unlikely that this was widespread. Fourth, treatment-seeking was low in most World Mental Health surveys. When it occurred, the reason for seeking treatment was not ADHD but a comorbid disorder.

Irrespective of whether the type of bias Dr Berg suggested exists in epidemiological surveys, our results imply that clinicians should look more seriously for ADHD in their adult patients than they have before. As more physicians screen for ADHD among adults presenting for treatment of other psychiatric disorders, the extent to which untreated adult ADHD exists among help-seekers will become apparent.

R. C. Kessler Department of Health Care Policy, Harvard Medical School, 180 Longwood Avenue, Boston, MA 02115, USA. Email: kessler@hcp.med.harvard.edu 